Chinese Journal of Organic Chemistry

NOTE

\title{
我脱氧胆酸含氮衍生物的合成及抗肿瘤活性研究
}

\author{
黄燕敏 ${ }^{a} \quad$ 姚秋翠 ${ }^{b} \quad$ 刘志平 ${ }^{a} \quad$ 甘春芳 ${ }^{a} \quad$ 郑嘉桦 ${ }^{a}$ 盛海兵 ${ }^{a}$ \\ 石海信 $c$ 崔建国*,a,c \\ ( ${ }^{a}$ 广西师范学院化学与材料科学学院 南宁 530001) \\ $\left(^{b}\right.$ 北部湾环境演变与资源利用重点实验室 广西师范学院 南宁 530219$)$ \\ ( ${ }^{c}$ 广西高校北部湾石油天然气资源有效利用重点实验室 钦州学院 钦州 535000)
}

\begin{abstract}
摘要 鹅脱氧胆酸的含氮衍生物能抑制多种癌细胞的增殖作用并能够诱导多种癌细胞的调亡. 从鹅去氧胆酸出发, 经 过酯化、Jones 试剂氧化、还原等反应, 分别在鹅去氧胆酸甾核的 3-位或 7-位引进肜基、甲氧肜基、芐氧肜基和含有不 同取代基的氨基硫脲等含氮基团，通过 IR、NMR 及 Ms 等现代分析方法对合成物进行了结构表征. 同时, 分别采用人 胃癌细胞(SGC-7901)、人肝癌细胞(Bel-7404)和前列腺癌细胞(PC-3)对合成产物及部分合成中间体进行体外抑制肿瘤细 胞生长增殖活性研究, 结果表明某些鹅脱氧胆酸含氮化合物对前列腺癌细胞(PC-3)和人体肝癌细胞(Bel 7404)具有较好 的抑制作用.
\end{abstract}

关键词 我脱氧胆酸; 含氮化合物; 抗肿瘤活性; 生理活性

\section{Synthesis and Antiproliferative Evaluation of Chenodeoxycholic Acid Containing-Nitrogen Derivatives}

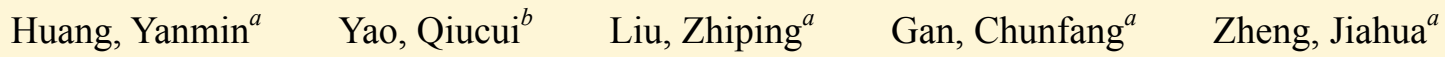 \\ Sheng, Haibing ${ }^{a} \quad$ Shi, Haishing ${ }^{c} \quad$ Cui, Jianguo ${ }^{*, a, c}$ \\ ( ${ }^{a}$ Chemistry and Materials Science College, Guangxi Teachers Education University, Nanning 53001) \\ ( ${ }^{b}$ Key Laboratory of Beibu GulfEnvironment Change and Resources Utilization, Guangxi Teachers Education University, \\ Nanning 530219) \\ ( ${ }^{c}$ Guangxi Colleges and University Key Laboratory of Beibu Gulf Oil and Natural Gas Resoure Effective Utilization, \\ Qinzhou University, Qinzhou 535000)
}

\begin{abstract}
Chenodeoxycholic acid nitrogen-containing derivatives display anti-tumor activities and induce apoptosis of the cacer cells. Some chenodeoxycholic acid derivatives possessing various nitrogen-containing substituent in 3- or 7-position of steroidal nucleus were designed and synthesized using chenodeoxycholic acid as starting materials. Their structures were characterized by IR, NMR and MS. Antiproliferative activities of the compounds were assayed against human gastric cancer cells (SGC-7901), human hepatic cancer (Bel-7404) and prostate cancer cell (PC-3) by MTT method. The results showed that some nitrogen-containing derivatives of chenodeoxycholic acid had better antiproliferative activities against Bel-7404 and PC-3 cells.
\end{abstract}

Keywords chenodeoxycholic acid; nitrogen-containing compounds; antiproliferative activity; bioactivity

近年来, 甾体类化合物作为抗肿瘤药物应用已经获 得极大关注, 在对甾体化合物的研究中人们发现, 当甾 体母核或者侧链引进氮原子或者含氮原子的官能团时, 所合成的化合物有着独特的生理活性 ${ }^{[1 \sim 6]}$. 在前期研究
中, 我们以不同的甾体母体如胆固醇、豆甾醇、孕甾醇 等为底物，在甾体的甾核或支链上引入不同的含氮官能 团，合成了不同类型的甾体含氮化合物，并对合成物进 行了体外抗肿瘤活性篮选，结果发现其中某些化合物具

*E-mail: cuijg1954@126.com

Received March 29, 2015; revised May 23, 2015; published online June 19, 2015.

Project supported by the National Natural Science Foundation of China (Nos. 21462009, 21562007) and the Opening Project of Guangxi Colleges and Universities Key Laboratory of Beibu Gulf Oil and Natural Gas Resource Effective Utilization (No. 2014KLOG09).

国家自然科学基金(No. 21462009)和广西高校北部湾石油天然气资源有效利用重点实验室开放课题(No. 2014KLOG09)资助项目. 
有较好的抗肿瘤活性 ${ }^{[7 \sim 12]}$.

胆酸是在肝细胞内由胆固醇转变而成的一种天然 甾体化合物. 它存在于肝肠循环的过程中, 有助于饮食 中脂质的吸收并且能调节控制胆固醇体内平衡的基因 表达. 我脱氧胆酸是胆汁酸的一种, 临床上常用于治疗 胆固醇结石, 但是最近研究表明, 我脱氧胆酸的含氮衍 生物具有抑制多种癌细胞的增殖作用 ${ }^{[13 \sim 15]}$, 并能够诱 导多种癌细胞调亡 ${ }^{[16]}$. 秦成勇等 ${ }^{[17]}$ 利用我脱氧胆酸衍 生物 $N$-[(3 $\alpha, 5 \beta, 7 \alpha)-3,7$ 二羟基-24-氧代胆甾烷-24-基]- $\beta$ 丙氨酸苄酯(HS-1200)作用于肝癌细胞和正常肝细胞, 结果发现鹅脱氧胆酸衍生物 HS-1200 对人肝肿瘤细胞 株 BEL74OZ 有显著的生长抑制作用, 该生长抑制作用 与 HS-1200 诱导肝肿瘤细胞调亡有关. 同时, HS-1200 对正常肝细胞株的生长增殖无明显抑制作用.

在前期研究中, 我们曾合成了一些我去氧胆酸的 A 环及 B 环内酰胺化合物, 并评估了它们的体外抗肿瘤活 性, 结果表明具有 3-茮氧肟醚取代结构的 B 环鹅去氧胆 酸内酰胺甲酯表现出很好的体外抗肿瘤活性 ${ }^{[18]}$. 在目 前的工作中, 本文进一步在鹅去氧胆酸甾核的 3-位或 7位引进不同的含氮官能团，如肜基、甲氧肜基、茮氧肟 基及含有不同取代基的缩氨基硫嫝等含氮基团, 并对合 成物进行体外抑制癌细胞活性测试, 分析研究在鹅去氧 胆酸母核的同一位置不同官能团或不同位置同一官能 团抑制肿瘤细胞生长的构效关系, 为进一步设计合成具 有更好抗肿瘤活性的新型抗癌药物提供理论参考.

\section{2 结果与讨论}

\section{1 化学部分}

Scheme 1 中列出了化合物 4 9 的合成路线. 首先, 先把我脱氧胆酸转换成为鹅脱氧胆酸甲酯, 然后采用 Jones 试剂氧化得到 3,7-二氧代我脱氧胆酸甲酯(3). 由 于在化合物 3 中 3-羰基和 7-羰基在甾核中所处的位置不 同, 7-位羰基由于受到甾核中 $\mathrm{A}$ 环及 $\mathrm{C}$ 环空间位阻的影 响, 因此活性较弱. 利用二者之间反应活性的差异, 控 制反应的温度和反应速度，可以使 3-羰基肜基化，而 7羰基保留. 这样, 通过化合物 3 与甲氧基肜或苄氧基肜 的反应, 分别得到化合物 $4 \sim 6$. 在化合物 4 的 ${ }^{1} \mathrm{H} N M R$ 谱中, 在 $\delta 3.778$ 处出现一个积分为 3 个 $\mathrm{H}$ 的单峰, 这是

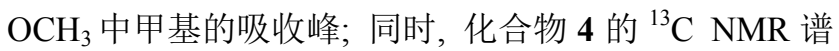
中在 $\delta 211.5 、 174.6$ 和 158.3 处分别出现了三个不饱和 碳的化学位移, 它们分别对应于化合物 4 中的 7-羰基、 24-羰基和 3-肜醚基的吸收, 由此可以证明化合物 4 为 3-甲氧肟基-7-氧代鹅去氧胆酸甲酯.

另外, 化合物 4 在 $\delta 3.02$ 处出现一个 dd 峰, 偶合常 数最大为 $15.6 \mathrm{~Hz}$, 这对应于 $\mathrm{C} 4-\alpha \mathrm{H}$ 的吸收(如果是<smiles>COC(=O)CC[C@H](C)C1CCC2C3C(C)[C@@H](O)CC4C[C@H](O)CCC4(C)C3CCC21C</smiles><smiles>COC(=O)CC[C@H](C)C1CCC2C3C(=O)CC4CC(=O)CC[C@]4(C)C3CC[C@@]21C</smiles>

3<smiles>[X]C1=C(C)CC[C@]2(C)C(C1)CC(O)C1C3CCC([C@H](C)CCC(=O)OC)C3(C)CC[C@H]12</smiles>

$4 \mathrm{X}=(\mathrm{Z})-\mathrm{NOCH}_{3}$ $5 \mathrm{X}=(\mathrm{Z})-\mathrm{NOCH}_{2} \mathrm{Ph}$ $6 \mathrm{X}=(E)-\mathrm{NOCH}_{2} \mathrm{Ph}$

$7 \mathrm{X}=(\mathrm{Z})-\mathrm{NOCH}_{3}$

$8 \mathrm{X}=(\mathrm{Z})-\mathrm{NOCH}_{2} \mathrm{Ph}$

$9 \mathrm{X}=(E)-\mathrm{NOCH}_{2} \mathrm{Ph}$

Reagents and conditions: (a) $\mathrm{MeOH} / \mathrm{HCl}$; (b) Jones, $0 \sim 5{ }^{\circ} \mathrm{C}$; (c) $\mathrm{NH}_{2} \mathrm{OCH}_{3} \cdot \mathrm{HCl}, 95 \% \mathrm{EtOH} / \mathrm{NaOAc} \cdot 3 \mathrm{H}_{2} \mathrm{O}, 55{ }^{\circ} \mathrm{C}$; (d) $\mathrm{NH}_{2} \mathrm{OCH}_{2} \mathrm{C}_{6} \mathrm{H}_{5} \cdot$ $\mathrm{HCl}, 95 \% \mathrm{EtOH} / \mathrm{NaOAc} \cdot 3 \mathrm{H}_{2} \mathrm{O}, 55{ }^{\circ} \mathrm{C}$; (e) $\mathrm{NaBH}_{4} / \mathrm{MeOH}$

图式 1 化合物 4 9 的合成

Scheme 1 The synthesis of compounds $4 \sim 9$

$\mathrm{C} 2-\alpha \mathrm{H}$ 的吸收, 应该是一个 $\mathrm{ddd}$ 峰), 由于甲氧基中 $\mathrm{O}$ 原 子负诱导效应的影响, 使它移向低场. 因此我们可以确 定化合物 4 为(3Z)-甲氧肜醚结构(图 1).

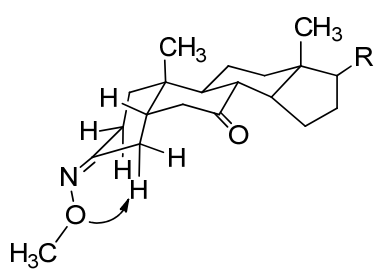

图 1 (3Z)-甲氧弜醚-7-氧代鹅去氧胆酸甲酯的稳定构象式 Figure 1 The stable configuration of methyl (3Z)-O-methylhydroximino-7-oxo-chenodeoxycholicate

在化合物 5 中, 在 ${ }^{1} \mathrm{H}$ NMR 谱中化学位移 $\delta 3.14$ 处 存在一个明显的 $\mathrm{dd}$ 峰 $(J=15.6,3.9 \mathrm{~Hz})$, 它对应于 $\mathrm{C} 4-\alpha \mathrm{H}$, 由于茮氧肜基中 $\mathrm{O}$ 原子的诱导影响, 它移动到 低场，因此化合物 5 为(3Z)-构型. 而在化合物 6 的 ${ }^{1} \mathrm{H}$ NMR 谱中, 在化学位移 $\delta 3.12$ 处出现一个较宽的 $\mathrm{d}$ 峰, 它对应于 6 的 $\mathrm{C} 2-\alpha \mathrm{H}$ 的化学位移, 此 $\mathrm{C} 2-\alpha \mathrm{H}$ 的化学位移 本应是一个 $\mathrm{ddd}$ 峰, 但是由于采用的是 $300 \mathrm{~Hz}$ 的核磁共 振仪进行测试, 所以在这里 $\mathrm{C} 2-\alpha \mathrm{H}$ 未能够充分地裂分, 仅表现为一个较宽的 $\mathrm{d}$ 峰. 从两者的分离产率来看, 化 合物 5 的产率为 $31 \%$, 化合物 6 的产率为 $42 \%$, 由于 $(E)-$ 
式异构体 $\mathbf{6}$ 比其 $(Z)$-式异构体 $\mathbf{5}$ 更加稳定, 所以为主要产 物, 同时 $(E)$-式异构体 $\mathbf{6}$ 比(Z)-式异构体 $\mathbf{5}$ 也具有较高的 熔点.

化合物 $4 \sim 6$ 采用 $\mathrm{NaBH}_{4}$ 进行还原分别得到相应的 产物 7 9. 化合物 7 9 的结构可通过它们的 IR、NMR 和 MS 谱分别得到表征. 从化合物 7 来看, 其前体化合 物 4 的 ${ }^{13} \mathrm{C}$ NMR 中 $\delta 211.5$ 的化学位移消失, 取而代之 的是在化合物 7 中出现一个 $\delta 68.3$ 的新吸收峰, 同时在 ${ }^{1} \mathrm{H}$ NMR 中 7 在 $\delta 3.87$ 处也出现了一个宽单峰, 它对应 于 C7-H 的化学位移, 因此证明化合物 4 的 7-羰基已经 被还原为 7-羟基. 由于仪器分辨率的原因, $\mathrm{C} 7-\mathrm{H}$ 只表 现出一个宽单峰，因此其立体结构无法确定.

为了进一步探索甾核上不同取代基位置对鹅脱氧 胆酸含氮衍生物抗肿瘤活性的影响. 在这里, 从鹅去氧 胆酸出发, 通过氧化形成 3,7-二酮(3), 然后在钴离子存 在的条件下采用 $\mathrm{NaBH}_{4}$ 选择性还原 3-位羰基得到化合 物 10. 由于在化合物 3 中 7-位羰基比 3-位羰基的活性要 弱，这里在钴离子存在的条件下，控制反应时间，可将 3 -位羰基还原为 3-位羟基，而 7-位羰基保持不变. 从 $\mathbf{1 0}$ 的 ${ }^{13} \mathrm{C}$ NMR 谱可以明显地看到, 原来化合物 3 在低场 $\delta$ 200 处存在的两个吸收峰, 现在化合物 10 中仅出现 $\delta$ 212.3 的 7-羰基吸收峰, 同时却在 $\delta 70.7$ 处出现了与羟基 相连碳的化学位移, 结合 ${ }^{1} \mathrm{H} N \mathrm{NR}$ 中 10 在 $\delta 3.59$ 处出现 的 dddd 峰化学位移, 说明 3-羰基已经被还原为 3-羟基. 同时, 从 $\mathrm{C} 3-\mathrm{H}$ 化学位移中最大偶合常数为 $15.3 \mathrm{~Hz}$ 可以 看到, $\mathrm{C} 3-\mathrm{H}$ 是处于 $\mathrm{A}$ 环的 $a$-键位置, 为 $\alpha$-构型氢, 即 $\mathrm{C} 3$-羟基处于 $e$-键位置, 为 $\beta$-构型羟基(Scheme 2 中化合 物 10 的结构).

然后，进一步对甾核的 7-位宸基进行官能团转换， 引入具有不同结构特征的含氮活性官能团, 共合成得到 6 个新的 $3 \beta$-着弪基-7-取代含氮鹅去氧胆酸甲酯. 合成物 的结构全部得到它们的 IR、NMR 及 MS 表征, 所分离 得到的产物为 $E$-构型产物, 这是因为受到甾核中 $\mathrm{C}$ 环和 $\mathrm{D}$ 环的影响, 如果生成 $Z$-构型产物时空间位阻较大, 因 此主要得到 $E$-构型产物. 以化合物 $\mathbf{1 1}$ 为例, 其在 $\delta 2.91$ 处出现一个 $d d$ 峰, 它对应于 C6- $\beta \mathrm{H}$ 的化学位移, 由于甲 氧基肜醚中氧原子的影响，它位移向低场.

\section{2 生物部分}

为了探索所合成化合物的体外抑制肿瘤细胞生长 增值活性，本文分别选用了人体前列腺癌细胞(PC-3)、 人体胃癌细胞(SGC 7901)和人体肝癌细胞(Bel 7404)三 种细胞株作为研究对象, 使用所合成化合物对上述肿瘤 细胞株进行了体外抑制肿瘤细胞生长增值活性篎选. 结 果如表 1 所示:

从表 1 中数据可以看到, 对应胃癌细胞株 SGC7901
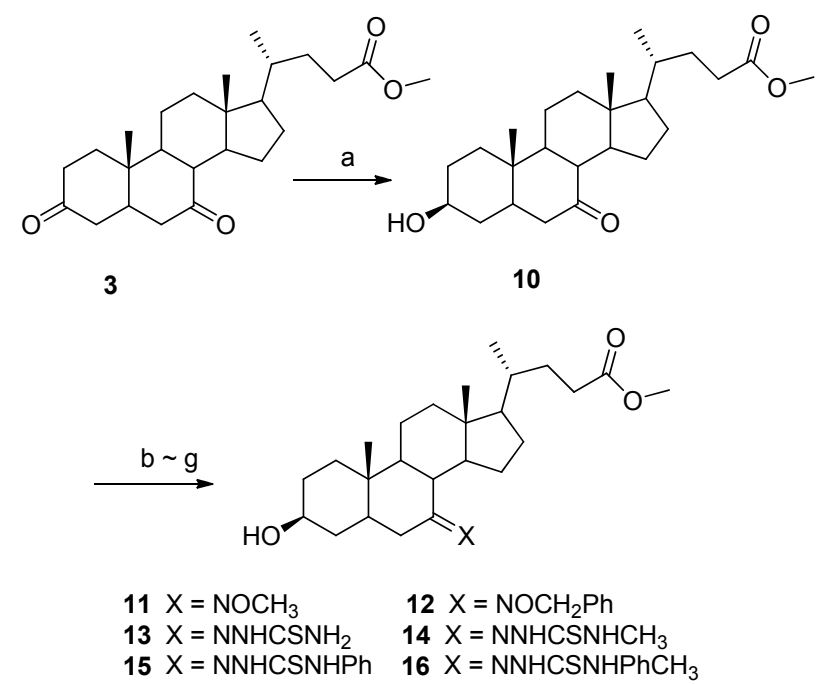

Reagents and conditions: (a) $\mathrm{NaBH}_{4} / \mathrm{CoCl}_{2} \cdot 6 \mathrm{H}_{2} \mathrm{O}, 0 \sim 5{ }^{\circ} \mathrm{C}$; (b) $\mathrm{CH}_{3} \mathrm{ONH}_{2} \bullet \mathrm{HCl}$, EtOH/AcOH, $75{ }^{\circ} \mathrm{C}$; (c) $\mathrm{PhCH}_{2} \mathrm{ONH}_{2} \cdot \mathrm{HCl}$, EtOH/ $\mathrm{AcOH}, 75{ }^{\circ} \mathrm{C}$; (d) $\mathrm{NH}_{2} \mathrm{NHCSNH} \mathrm{H}_{2}$, EtOH/AcOH, $75{ }^{\circ} \mathrm{C}$; (e) $\mathrm{NH}_{2} \mathrm{NH}-$ $\mathrm{CSNHCH}_{3}, \mathrm{EtOH} / \mathrm{AcOH}, 75{ }^{\circ} \mathrm{C}$; (f) $\mathrm{NH}_{2} \mathrm{NHCSNHPh}, \mathrm{EtOH} / \mathrm{AcOH}$, $75{ }^{\circ} \mathrm{C}$; (g) $\mathrm{NH}_{2} \mathrm{NHCSNHPhCH}$, EtOH/AcOH, $75{ }^{\circ} \mathrm{C}$

图式 2 化合物 $11 \sim 16$ 的合成

Scheme 2 The synthesis of compounds 11 16

表 1 含氮鹅脱氧胆酸化合物抗肿瘤活性测试结果(MTT 方 法) $\left[\mathrm{IC}_{50} /\left(\mu \mathrm{mol} \cdot \mathrm{L}^{-1}\right)\right]^{a}$

Table 1 In vitro antiproliferative activities $\left[\mathrm{IC}_{50} /\left(\mu \mathrm{mol} \cdot \mathrm{L}^{-1}\right)\right]$ of target compounds

\begin{tabular}{cccc}
\hline Compound & SGC-7901 & Bel-7404 & PC-3 \\
\hline $\mathbf{8}$ & $>100$ & 15.7 & 13.8 \\
$\mathbf{9}$ & $>100$ & 47.2 & ND $^{b}$ \\
$\mathbf{1 1}$ & 34.6 & 32.3 & 55.4 \\
$\mathbf{1 2}$ & $>100$ & 13.8 & 15.7 \\
$\mathbf{1 3}$ & 54.5 & 58.7 & 46.1 \\
$\mathbf{1 4}$ & 48.8 & $>100$ & 30.5 \\
$\mathbf{1 5}$ & $>100$ & $>100$ & $>100$ \\
$\mathbf{1 6}$ & $>100$ & $>100$ & $>100$ \\
Cisplatin & 6.7 & 10.1 & 56.4 \\
\hline
\end{tabular}

${ }^{a}$ Data represent the mean values of three independent determinations; ${ }^{b}$ Not determined.

来说，除了化合物 $11 、 13$ 和 14 表现出中等程度的细胞 毒性外，其它化合物对该细胞基本上没有生长增殖抑制 活性. 而对于肝癌细胞株 Bel 7404 和人体前列腺癌细胞 株 PC-3 来说, 化合物 8 9 和 11 13 都显示出明显的细 胞毒性，其中具有茮氧肟醚取代基结构的化合物 $\mathbf{8}$ 和 12 表现出最好的抑制活性. 另外从化合物 8 和 12 相比较可 以看到，这两者苄氧肜醚基在甾核中的取代位置对化合 物细胞毒性没有明显的影响. 从取代官能团对增进化合 物细胞毒性的影响来看, 在这里苄氧肟醚基是一个最好 的取代基，甲氧肜醚基总体来说比缩氨硫艮基要好，当 在缩氨硫腿取代基中的 4-位氨基引入取代基后，化合物 的抗肿瘤活性降低，其中苯基取代比甲基取代活性降低 
的效果远远要大. 对于 SGC7901 和 Bel 7404 细胞来说, 这些化合物的抑制生长增殖活性明显低于阳性对照物 顺铂, 但是对于前列腺癌细胞(PC-3)来说, 化合物 8 和 12 的抑制活性都大于顺铂.

与胃癌细胞株相比较, 这些化合物对肝癌和前列腺 细胞株表现出较好的抑制生长活性, 主要原因可能是由 于胆酸是参与肝肠循环中的一种重要物质, 因此, 我脱 氧胆酸的含氮衍生物主要作用于肝肠系统, 所以它们对 肝癌肿瘤细胞株表现出较好的抑制活性.

\section{3 结论}

从鹅脱氧胆酸出发, 经过酯化、Jones 试剂氧化、还 原等反应，然后进一步对羰基进行官能团转换，合成了 系列具有不同取代位置的鹅脱氧胆酸含氮衍生物, 并通 过 IR、NMR 及 MS 等现代分析方法对合成物进行了结 构表征. 分别采用人胃癌细胞(SGC-7901)、人肝癌细胞 (Bel-7404)和前列腺癌细胞(PC-3)对合成产物及部分合 成中间体进行了体外抑制肿瘤细胞生长增殖活性研究. 结果表明某些鹅脱氧胆酸含氮化合物对肝癌及前列腺 癌细胞具有较好的抑制作用, 而对胃癌细胞株 SGC7901 基本没有活性. 它可能与鹅脱氧胆酸的肝肠 循环作用有关. 具有苄氧肟醚基取代的化合物具有最好 的抑制活性，另外当在缩氨硫脲取代基中的 4-位氨基引 入取代基后, 化合物的抑制活性降低. 研究结果为今后 设计合成具有更好抗肿瘤活性的甾体化合物提供了有 用的参考.

\section{4 实验部分}

\section{1 化学合成部分}

\subsection{1 试剂和仪器}

合成所用试剂如无特别说明均为分析纯, 溶剂按常 规方法进行处理干燥. IR 测定采用 Nicolet IS-10 傅立叶 红外光谱仪; 熔点测定采用 $\mathrm{X}_{6}$ 显微熔点测定仪, 温度计 未经校正; ${ }^{1} \mathrm{H} \mathrm{NMR},{ }^{13} \mathrm{C} \mathrm{NMR}$ 测定采用德国 Bruker AV-300 型超导核磁共振仪; 高分辨质谱采用美国 Agilent 6210 TOFMS 质谱仪测定.

4.1.2 (3Z)- 甲氧肜醚-7-氧代我鸟去氧胆酸甲酯(4)的合 成

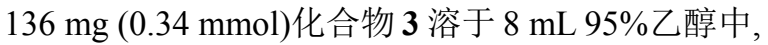
升温到 $55{ }^{\circ} \mathrm{C}$. 加入 $138 \mathrm{mg}(1.014 \mathrm{mmol}) \mathrm{NaOAc} \cdot 3 \mathrm{H}_{2} \mathrm{O}$, 完全溶解后一次性加入 $133 \mathrm{mg}(1.84 \mathrm{mmol})$ 的 $\mathrm{NH}_{2} \mathrm{OCH}_{3} \bullet \mathrm{HCl}$, 保持反应温度 $55^{\circ} \mathrm{C}, \mathrm{TLC}$ 检测 $\left(V_{\text {甲醇 }}\right.$ : $\left.V_{\text {二氯甲烷 }}=1: 20\right)$ 反应进程, 反应 $0.5 \mathrm{~h}$ 后无原料点. 减压 蒸去大部分乙醇, 加入适量水, 用二氯甲烷萃取, 合并 有机相. 依次用水、饱和食盐水洗至中性, 无水硫酸钠
干燥, 减压蒸去溶剂, 粗产品柱层析分离 $(V$ 乙酸乙酯： $V_{\text {石油瞵 }}=2:$ 1)得到白色固体化合物 $458 \mathrm{mg}$, 产率 $40 \%$. m.p. 83 85 ${ }^{\circ} \mathrm{C} ;{ }^{1} \mathrm{H}$ NMR $\left(\mathrm{CDCl}_{3}, 300 \mathrm{MHz}\right) \delta$ : 0.66 (s, $\left.3 \mathrm{H}, 18-\mathrm{CH}_{3}\right), 0.91\left(\mathrm{~d}, J=6.3 \mathrm{~Hz}, 3 \mathrm{H}, 21-\mathrm{CH}_{3}\right), 1.23$ (s, $\left.3 \mathrm{H}, 19-\mathrm{CH}_{3}\right), 2.43$ (t, $\left.J=11.4 \mathrm{~Hz}, 1 \mathrm{H}, \mathrm{C} 8-\mathrm{H}\right), 2.84$ (dd, $J=12.6 \mathrm{~Hz}, 6.0,1 \mathrm{H}, \mathrm{C} 6-\beta \mathrm{H}), 3.02(\mathrm{dd}, J=15.6 \mathrm{~Hz}$, $4.5,1 \mathrm{H}, \mathrm{C} 4-\beta \mathrm{H}), 3.65\left(\mathrm{~s}, 1 \mathrm{H}, \mathrm{COOCH}_{3}\right), 3.78(\mathrm{~s}, 3 \mathrm{H}$, $\left.\mathrm{NOCH}_{3}\right) ;{ }^{13} \mathrm{C} \mathrm{NMR}\left(\mathrm{CDCl}_{3}, 75 \mathrm{MHz}\right) \delta: 211.5$ (7-C), 174.6 (24-C), 158.3 (3-C), $61.1\left(\mathrm{NOCH}_{3}\right), 54.7$ (17-C), 51.5 (9-C), $49.5\left(\mathrm{OCH}_{3}\right), 48.8$ (8-C), 46.3 (14-C), 45.1 (13-C), 42.6 (6-C), 42.5 (10-C), 38.8 (5-C), 35.9 (12-C), 35.8 (20-C), 35.2 (23-C), 31.0 (22-C), 30.9(4-C), 28.3 (16-C), 26.5(1-C), 26.4(2-C), 24.8 (15-C), 22.9 (11-C), 21.9 (21-C), 18.4 (19-C), 12.1 (18-C); IR (KBr) v: 3452, 3399, 2949, 2868, 2810, 1740, 1711, 1642, 1466, 1450, 1380, 1348, 1315, 1217, 1053, 867, 890, 820, $677 \mathrm{~cm}^{-1}$; ESI-MS $m / z: 454.2(\mathrm{M}+23)^{+}$; HREIMS calcd for $\mathrm{C}_{26} \mathrm{H}_{41} \mathrm{NNaO}_{4}[\mathrm{M}+\mathrm{Na}]^{+}$454.2933; found 454.2928.

4.1.3 3-芳氧肜醚-7-氧代我鸟去氧胆酸甲酯(5 和 6 ) 的 合成

在连有球形冷凝管的反应瓶中将 $250 \mathrm{mg}(0.62$

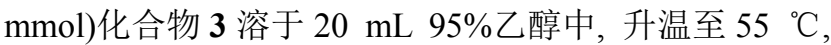
加入 $253 \mathrm{mg}(1.87 \mathrm{mmol}) \mathrm{NaOAc} \cdot 3 \mathrm{H}_{2} \mathrm{O}$, 完全溶解后一 次性加入 $364 \mathrm{mg}(1.26 \mathrm{mmol})$ 的 $\mathrm{NH}_{2} \mathrm{OC}_{6} \mathrm{H}_{5} \bullet \mathrm{HCl}$, 保持 反应温度 $55{ }^{\circ} \mathrm{C}, \mathrm{TLC}$ 检测 $\left(V_{\text {甲醇 }}: V_{\text {二氯甲烷 }}=1: 20\right)$, 反应 $3 \mathrm{~h}$ 后无原料点. 减压蒸去大部分乙醇, 加入适量水, 用 乙酸乙酯萃取, 合并有机相. 依次用水、饱和食盐水洗 至中性, 无水硫酸钠干燥, 减压蒸去溶剂, 粗产品柱层 析分离 $(V$ 乙酸乙酯 $: V$ 石油瞵 $=2: 1)$ 得到 $98 \mathrm{mg}$ 白色固体 (3Z)-茮氧肜基-7-氧代我去氧胆酸甲酯(5)和 $132 \mathrm{mg}$ (3E)-茮氧肜基-7-氧代我去氧胆酸甲酯(6).

化合物 5: 产率 31\%. m.p. $75 \sim 77{ }^{\circ} \mathrm{C} ;{ }^{1} \mathrm{H}$ NMR $\left(\mathrm{CDCl}_{3}, 300 \mathrm{MHz}\right) \delta: 0.68\left(\mathrm{~s}, 3 \mathrm{H}, 18-\mathrm{CH}_{3}\right), 0.93(\mathrm{~d}, J=6.0$ $\left.\mathrm{Hz}, 3 \mathrm{H}, 21-\mathrm{CH}_{3}\right), 1.24\left(\mathrm{~s}, 3 \mathrm{H}, 19-\mathrm{CH}_{3}\right), 2.48 \sim 2.31(\mathrm{~m}$, $2 \mathrm{H}, \mathrm{C} 6-\alpha \mathrm{H}$ and $\mathrm{C} 5-\mathrm{H}), 2.86(\mathrm{dd}, J=12.6,5.7 \mathrm{~Hz}, 1 \mathrm{H}$, C6- $\beta \mathrm{H}), 3.14$ (dd, $J=15.6,3.9 \mathrm{~Hz}, 1 \mathrm{H}, \mathrm{C} 4-\beta \mathrm{H}), 3.67$ (s, $3 \mathrm{H}, \mathrm{OCH}_{3}$ ), 5.04 (s, 2H, $\mathrm{OCH}_{2}$ ), 7.33 (br s, $\left.5 \mathrm{H}, \mathrm{Ph}-\mathrm{H}\right) ;{ }^{13} \mathrm{C}$ NMR $\left(\mathrm{CDCl}_{3}, 75 \mathrm{MHz}\right) \delta$ : 211.6 (7-C), 174.7 (24-C), 158.9 (3-C), 138.0 (1'-C), 128.3 (3'-C, 5'-C), 127.9 (2'-C, 6'-C), 127.7 (4'-C), 75.3 (NOC), 54.7 (17-C), 51.5 (9-C), $51.4\left(\mathrm{OCH}_{3}\right), 49.5$ (8-C), 48.8 (14-C), 46.3 (13-C), 45.1 (10-C), 42.6 (6-C), 42.5 (5-C), 38.9 (12-C), 35.8 (20-C), 35.2 (22-C), 31.0 (23-C), 30.9 (4-C), 28.3 (16-C), 26.7 (1-C), 26.4 (2-C), 24.8 (15-C), 22.9 (11-C), 21.9 (21-C), 18.3 (19-C), 12.0 (18-C); IR (KBr) v: 3432, 3395, 2945, 
2880, 1732, 1699, 1638, 1466, 1433, 1409, 1372, 1274, 1229, 1172, 1045, 1012, 931, 902, 694, 624, $465 \mathrm{~cm}^{-1}$; ESI-MS $m / z$ : $530.3(\mathrm{M}+23)^{+}$; HREIMS calcd for $\mathrm{C}_{32} \mathrm{H}_{45} \mathrm{NNaO}_{4}[\mathrm{M}+\mathrm{Na}]^{+}$530.3246, found 530.3231 .

化合物 6: 产率 $42 \%$. m.p. $80 \sim 82{ }^{\circ} \mathrm{C} ;{ }^{1} \mathrm{H}$ NMR $\left(\mathrm{CDCl}_{3}, 300 \mathrm{MHz}\right) \delta: 0.68\left(\mathrm{~s}, 3 \mathrm{H}, 18-\mathrm{CH}_{3}\right), 0.94(\mathrm{~d}, J=6.0$ $\left.\mathrm{Hz}, 3 \mathrm{H}, 21-\mathrm{CH}_{3}\right), 1.23$ (s, 3H, 19- $\left.\mathrm{CH}_{3}\right), 2.47 \sim 2.32(\mathrm{~m}$, $2 \mathrm{H}, \mathrm{C} 6-\alpha \mathrm{H}$ and $\mathrm{C} 5-\mathrm{H}), 2.86(\mathrm{~d}, J=9.3 \mathrm{~Hz}, 1 \mathrm{H}, \mathrm{C} 6-\beta \mathrm{H})$, $3.12(\mathrm{~d}, J=13.8 \mathrm{~Hz}, 1 \mathrm{H}, \mathrm{C} 2-\beta \mathrm{H}), 3.68\left(\mathrm{~s}, 3 \mathrm{H}, \mathrm{OCH}_{3}\right), 5.05$ (s, $\left.2 \mathrm{H}, \mathrm{OCH}_{2}\right), 7.34$ (br s, $\left.5 \mathrm{H}, \mathrm{Ph}-\mathrm{H}\right) ;{ }^{13} \mathrm{C} \mathrm{NMR}\left(\mathrm{CDCl}_{3}, 75\right.$ MHz) $\delta: 211.7$ (7-C), 174.7 (24-C), 159.3 (3-C), 138.1 (1'-C), 128.3 (3'-C, 5'-C), 127.9 (2'-C, 6'-C), 127.7 (4'-C), 75.3 (NOC), 54.7 (17-C), $51.5\left(\mathrm{OCH}_{3}\right), 49.5$ (9-C), 48.9 (8-C), 47.5 (14-C), 45.0 (13-C), 42.7 (10-C), 42.4 (6-C), 38.9 (5-C), 35.9 (12-C), 35.2 (20-C), 34.8 (22-C), 33.2 (23-C), 31.0 (4-C), 30.9 (16-C), 28.3 (1-C), 24.8 (2-C), 22.8 (15-C), 21.9 (11-C), 20.4 (21-C), 18.4 (19-C), 12.1 (18-C); IR (KBr) v: 3436, 3395, 2945, 2880, 1732, 1703, 1454, 1446, 1384, 1360, 1307, 1200, 1049, 996, 902, 886, $829,726,698,616,567 \mathrm{~cm}^{-1}$; HREIMS calcd for $\mathrm{C}_{32} \mathrm{H}_{45^{-}}$ $\mathrm{NNaO}_{4}[\mathrm{M}+\mathrm{Na}]^{+}$530.3246, found 530.3231.

4.1.4 3-甲氧肜醚-7-羟基我去氧胆酸甲酯(7)的合成

向反应瓶中加入 $250 \mathrm{mg}(0.58 \mathrm{mmol})$ 化合物 4 , 用 $50 \mathrm{~mL}$ 无水 $\mathrm{CH}_{3} \mathrm{OH}$ 溶解完全后, $10 \mathrm{~min}$ 内分批加入 $\mathrm{NaBH}_{4} 66 \mathrm{mg}(1.740 \mathrm{mmol}), \mathrm{TLC}$ 监测 $\left(V_{\text {甲壀 }}: V_{\text {二氯甲烧 }}=\right.$ $1: 10$ ), 继续反应 $15 \mathrm{~min}$ 至无原料点, 加入 $1 \mathrm{~mol} / \mathrm{L} \mathrm{HCl}$ 中和反应液使反应终止. 减压蒸出大部分甲醇, 加适量 水, 用乙酸乙酯萃取. 合并有机层, 经水洗、饱和食盐水 洗至中性, 无水硫酸钠干燥. 减压蒸出溶剂, 得白色固 体, 柱层析分离 $\left(V_{\text {甲陪 }}: V_{\text {二氯甲烷 }}=1: 40\right)$ 得到化合物 7100 $\mathrm{mg}$, 产率 40\%. m.p. 96 98 ${ }^{\circ} \mathrm{C} ;{ }^{1} \mathrm{H}$ NMR $\left(\mathrm{CDCl}_{3}, 300\right.$ MHz) $\delta: 0.67\left(\mathrm{~s}, 3 \mathrm{H}, 18-\mathrm{CH}_{3}\right), 0.92(\mathrm{~d}, J=6.0 \mathrm{~Hz}, 6 \mathrm{H}$, $\left.21-\mathrm{CH}_{3}\right), 0.93$ (s, $\left.3 \mathrm{H}, 19-\mathrm{CH}_{3}\right), 2.40 \sim 2.30(\mathrm{~m}, 1 \mathrm{H}, \mathrm{C} 5-\mathrm{H})$, 2.91 (dd, $J=12.9,4.5 \mathrm{~Hz}, 1 \mathrm{H}, \mathrm{C} 4-\alpha \mathrm{H}), 3.10$ (t, $J=14.4$ $\mathrm{Hz}, 1 \mathrm{H}, \mathrm{C} 4-\beta \mathrm{H}), 3.66\left(\mathrm{~s}, 3 \mathrm{H}, \mathrm{OCH}_{3}\right), 3.79$ (s, 3H, $\mathrm{NOCH}_{3}$ ), 3.87 (br s,1H, C7-H); ${ }^{13} \mathrm{C}$ NMR $\left(\mathrm{CDCl}_{3}, 75\right.$ MHz) $\delta: 174.7$ (24-C), 161.6 (3-C), 68.3 (7-C), 60.9 $\left(\mathrm{NOCH}_{3}\right), 55.7$ (17-C), $51.5(14-\mathrm{C}), 50.3\left(\mathrm{OCH}_{3}\right), 43.5$ (13-C), 42.7 (9-C), 39.5 (8-C), 39.3 (10-C), 36.1 (12-C), 35.8 (5-C), 35.3 (20-C), 35.2 (6-C), 34.2 (4-C), 33.0 (22-C), 31.0 (23-C), 30.9 (16-C), 28.1 (1-C), 23.7 (2-C), 22.3 (15-C), 20.8 (11-C), 20.6 (21-C), 18.3 (19-C), 11.8 (18-C); IR (KBr) v: 3374, 2937, 2855, 1744, 1634, 1540, 1462, 1372, 1258, 1168, 1057, 1012, 914, 878, 829, 730, 694, $616 \mathrm{~cm}^{-1}$; HREIMS calcd for $\mathrm{C}_{26} \mathrm{H}_{44} \mathrm{NO}_{4}[\mathrm{M}+\mathrm{H}]^{+}$
434.3270, found 434.3287.

\subsubsection{3-芐氧肟醚-7-差基鹅去氧胆酸甲酯 $(8)$ 的合成}

向反应瓶中加入 $238 \mathrm{mg}(0.47 \mathrm{mmol})$ 化合物 $\mathbf{5}$, 用 $50 \mathrm{~mL}$ 无水 $\mathrm{CH}_{3} \mathrm{OH}$ 溶解完全后, $10 \mathrm{~min}$ 内分批加入 $\mathrm{NaBH}_{4} 54 \mathrm{mg}(1.41 \mathrm{mmol}), \quad$ TLC 监测 $\left(V_{\text {甲醇 }}: V_{\text {二氧甲㛡 }}=\right.$ $1: 10)$, 继续反应 $15 \mathrm{~min}$ 至无原料点, 加入 $1 \mathrm{~mol} / \mathrm{L} \mathrm{HCl}$ 中和反应液使反应终止. 减压蒸出大部分甲醇, 加适量 水, 用乙酸乙酯萃取. 合并有机层, 经水洗, 饱和食盐 水洗至中性, 无水硫酸钠干燥. 减压蒸出溶剂得白色固

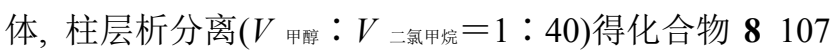
$\mathrm{mg}$, 产率 45\%. m.p. $96 \sim 98{ }^{\circ} \mathrm{C} ;{ }^{1} \mathrm{H}$ NMR $\left(\mathrm{CDCl}_{3}, 300\right.$ MHz) $\delta: 0.68\left(\mathrm{~s}, 3 \mathrm{H}, 18-\mathrm{CH}_{3}\right), 0.94(\mathrm{~d}, J=6.0 \mathrm{~Hz}, 3 \mathrm{H}$, $\left.21-\mathrm{CH}_{3}\right), 0.94\left(\mathrm{~s}, 3 \mathrm{H}, 19-\mathrm{CH}_{3}\right), 2.41 \sim 2.23(\mathrm{~m}, 2 \mathrm{H}$, C23-H), 2.81 (t, $J=13.2 \mathrm{~Hz}, 1 \mathrm{H}, \mathrm{C} 4-\alpha \mathrm{H}), 3.08$ (dd, $J=$ $15.9,4.8 \mathrm{~Hz}, 1 \mathrm{H}, \mathrm{C} 4-\beta \mathrm{H}$ ), 3.66 (s, $3 \mathrm{H}, \mathrm{OCH}_{3}$ ), 3.87 (br s, $1 \mathrm{H}, \mathrm{C} 7-\mathrm{H}), 5.05\left(\mathrm{~s}, 2 \mathrm{H}, \mathrm{OCH}_{2}\right), 7.35 \sim 7.27(\mathrm{~m}, 1 \mathrm{H}, \mathrm{Ph}-\mathrm{H})$; ${ }^{13} \mathrm{C} \mathrm{NMR}\left(\mathrm{CDCl}_{3}, 75 \mathrm{MHz}\right) \delta$ : 174.8 (24-C), 161.8 (3-C), 138.4 (1'-Ph-C), 128.3 (3'-Ph-C, 5'-Ph-C), 127.9 (2'-Ph-C, 6'-Ph-C), 127.5 (4'-Ph-C), 75.1 (Ph-C-O), 68.4 (7-C), 55.8 (17-C), 51.5 (14-C), $50.3\left(\mathrm{OCH}_{3}\right), 42.8$ (13-C ), 41.7 (9-C), 39.5 (8-C), 39.3 (10-C), 37.2(12-C), 35.7 (5-C), 35.4 (20-C), 34.1 (6-C), 33.1 (4-C ), 31.0 (22-C), 30.9 (23-C), 29.1(16-C), 28.1 (1-C), 26.9 (2-C), 23.7 (15-C), 22.4 (11-C), 20.9 (21-C), 18.3 (19-C), 11.8 (18-C); IR (KBr) v: 3534, 2945, 2859, 1723, 1654, 1425, 1368, 1217, 1155, $1045 \mathrm{~cm}^{-1}$; HREIMS calcd for $\mathrm{C}_{32} \mathrm{H}_{47} \mathrm{NNaO}_{4}[\mathrm{M}+\mathrm{Na}]^{+}$ 532.3403, found 532.3401.

4.1.63-芳氧肜醚-7-羟基我鸟去氧胆酸甲酯(9)的合成

向反应瓶中加入 $200 \mathrm{mg}(0.39 \mathrm{mmol})$ 化合物 6 , 用 $50 \mathrm{~mL}$ 无水 $\mathrm{CH}_{3} \mathrm{OH}$ 溶解完全后, $10 \mathrm{~min}$ 内分批加入 $\mathrm{NaBH}_{4} 45 \mathrm{mg}(1.18 \mathrm{mmol}), \mathrm{TLC}$ 监测 $\left(V_{\text {甲䁨 }}: V_{\text {二氯甲㛡 }}=1:\right.$ 10), 继续反应 $15 \mathrm{~min}$ 至无原料点, 加入 $1 \mathrm{~mol} / \mathrm{L} \mathrm{HCl}$ 中 和反应液使反应终止. 减压蒸出大部分甲醇, 加适量水, 用乙酸乙酯萃取. 合并有机层, 经水洗, 饱和食盐水洗 至中性, 无水硫酸钠干燥. 减压蒸出溶剂得白色固体, 柱层析分离 $\left(V_{\text {甲醉 }}: V_{\text {二氢丹琓 }}=1: 40\right)$ 得到化合物 $990 \mathrm{mg}$, 产率 $45 \%$. m.p. 96 98 ${ }^{\circ} \mathrm{C} ;{ }^{1} \mathrm{H} \mathrm{NMR}\left(\mathrm{CDCl}_{3}, 300 \mathrm{MHz}\right)$ $\delta: 0.68\left(\mathrm{~s}, 3 \mathrm{H}, 18-\mathrm{CH}_{3}\right), 0.94\left(\mathrm{~d}, J=6.3 \mathrm{~Hz}, 3 \mathrm{H}, 21-\mathrm{CH}_{3}\right)$, $0.94\left(\mathrm{~s}, 3 \mathrm{H}, 19-\mathrm{CH}_{3}\right), 2.42 \sim 2.20(\mathrm{~m}, 2 \mathrm{H}, \mathrm{C} 23-\mathrm{H}), 3.16 \sim$ $3.00(\mathrm{~m}, 2 \mathrm{H}, \mathrm{C} 2-\mathrm{H}), 3.67$ (s, 3H, $\left.\mathrm{OCH}_{3}\right), 3.87$ (br s, $1 \mathrm{H}$, $\left.\mathrm{C}_{7}-\mathrm{H}\right), 5.05\left(\mathrm{~s}, 2 \mathrm{H}, \mathrm{OCH}_{2} \mathrm{Ph}\right) ; 7.35 \sim 7.26(\mathrm{~m}, 5 \mathrm{H}, \mathrm{Ph}-\mathrm{H})$; ${ }^{13} \mathrm{C} \mathrm{NMR}\left(\mathrm{CDCl}_{3}, 75 \mathrm{MHz}\right) \delta$ : 174.8 (24-C), 162.2 (3-C), 138.4 (1'-Ph-C), 128.3 (3'-Ph-C, 5'-Ph-C), 127.8 (2'-Ph-C, 6'-Ph-C), 127.5 (4'-Ph-C), 75.0 (Ph-C-O), 68.3 (7-C), 55.8 (17-C), 51.5 (14-C), $50.3\left(\mathrm{OCH}_{3}\right), 43.4$ (13-C), 42.7 (9-C), 
39.6 (8-C), 39.3 (10-C), 36.1 (12-C), 35.8 (5-C), 35.7 (20-C), 35.4 (6-C), 35.2 (4-C), 34.2 (22-C), 33.0 (23-C), 31.0 (16-C), 28.1 (1-C), 23.7 (2-C), 22.3 (15-C), 20.9 (11-C), 20.8 (21-C), 18.3 (19-C), 11.8 (18-C); IR (KBr) v: 3443, 2925, 2864, 1740, 1634, 1429, 1372, 1298, 1160 $\mathrm{cm}^{-1}$; HREIMS calcd for $\mathrm{C}_{32} \mathrm{H}_{48} \mathrm{NO}_{4}[\mathrm{M}+1]^{+}$510.3583, found 510.3575 .

\section{$4.1 .73 \beta$-差基-7-氧代鹅去氧胆酸甲酯(10)的合成}

将 $200 \mathrm{mg}(0.50 \mathrm{mmol})$ 化合物 3 溶于 $15 \mathrm{~mL}$ 甲醇, 溶 解完全后, 加入 $118 \mathrm{mg}(0.50 \mathrm{mmol}) \mathrm{CoCl}_{2} \cdot 6 \mathrm{H}_{2} \mathrm{O}$, 溶液 由无色变为淡紫红色, 在室温下搅拌 $20 \mathrm{~min}$ 后逐渐加入 $56 \mathrm{mg}$ (1.49 mmol) $\mathrm{NaBH}_{4}$, 溶液立即变为黑色, 同时有 大量气泡放出, TLC 跟踪反应 $\left(V_{\text {乙配酔 }}: V_{\text {石油硪 }}=1: 1\right), 40$ $\min$ 后无原料点, 用 $1 \mathrm{~mol} / \mathrm{L}$ 的盐酸中和反应液使反应 终止. 减压蒸去大部分甲醇, 加适量水, 立即有大量白 色浑浊生成, 用乙酸乙酯萃取, 合并有机层, 分别用饱 和碳酸氢钠溶液、水、饱和食盐水各洗一次, 最后用无 水硫酸钠干燥. 减压除去溶剂得白色固体, 柱层析分离

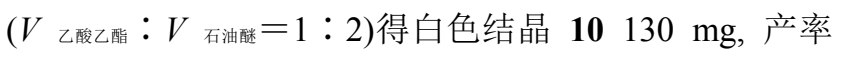
64.3\%. m.p. $67 \sim 68{ }^{\circ} \mathrm{C} ;{ }^{1} \mathrm{H}$ NMR $\left(\mathrm{CDCl}_{3}, 300 \mathrm{MHz}\right) \delta$ : 0.64 (s, 3H, 18- $\left.\mathrm{CH}_{3}\right), 0.91$ (d, $J=6.3 \mathrm{~Hz}, 3 \mathrm{H}, 21-\mathrm{CH}_{3}$ ), $1.19\left(\mathrm{~s}, 3 \mathrm{H}, 19-\mathrm{CH}_{3}\right), 2.42 \sim 2.30\left(\mathrm{~m}, 2 \mathrm{H}, \mathrm{C}_{6}-\mathrm{H}\right), 2.85(\mathrm{dd}$, $J=12.6,6.0,1 \mathrm{H}, \mathrm{C}_{8}-\mathrm{H}$ ), 3.59 (dddd, $J=15.3,10.5,6.0$, $\left.4.5 \mathrm{~Hz}, 1 \mathrm{H}, \mathrm{C}_{3}-\mathrm{H}\right), 3.66$ (s, $\left.3 \mathrm{H}, \mathrm{OCH}_{3}\right) ;{ }^{13} \mathrm{C} \mathrm{NMR}\left(\mathrm{CDCl}_{3}\right.$, 75MHz) $\delta: 212.3$ (7-C), 174.7 (24-C), 70.7 (3-C), 54.7

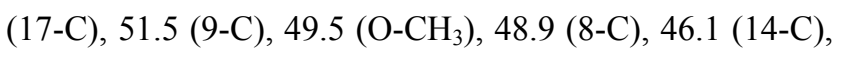
45.4 (6-C), 42.7 (5-C), 42.6 (13-C), 38.9 (4-C), 37.3 (12-C), 35.2 (20-C), 35.1 (10-C), 34.1 (1-C), 31.0 (22-C), 30.9 (23-C), 29.8 (2-C), 28.3 (16-C), 24.8 (15-C), 23.0 (11-C), 21.7 (21-C), 18.3 (19-C), 12.0 (18-C); IR (KBr) v: 3517, 2921, 2868, 1707, 1638, 1425, 1376, 1294, 1254, 1200, 1155, 1070, 1004, 980, $898 \mathrm{~cm}^{-1}$; ESI-MS $\mathrm{m} / \mathrm{z}$ : $427.3\left(\mathrm{M}^{+}+\mathrm{Na}\right)$; HREIMS calcd for $\mathrm{C}_{25} \mathrm{H}_{40} \mathrm{NaO}_{4} \mathrm{CM}+$ $\mathrm{Na}]^{+}$427.2824, found 427.2812.

4.1.8 化合物 11 16 合成的一般程序

$0.34 \mathrm{mmol}$ 化合物 $\mathbf{1 0}$ 溶于 $10 \mathrm{~mL} 95 \%$ 乙醇中, 升温 至 $75{ }^{\circ} \mathrm{C}$ 后加入 $1.00 \mathrm{mmol} \mathrm{NaAc} \cdot 3 \mathrm{H}_{2} \mathrm{O}$, 完全溶解后一 次性加入 $1.00 \mathrm{mmol}$ 的含氮试剂, 保持反应温度 $75{ }^{\circ} \mathrm{C}$, $\mathrm{TLC}$ 检测 $\left(V_{\text {甲䀦 }}: V_{\text {二攻甲㛡 }}=1: 20\right)$ 反应至无原料点. 加入 适量水终止反应, 减压蒸去大部分乙醇, 然后用二氯甲 烷萃取. 合并有机相, 依次用水、饱和食盐水洗至中性, 无水硫酸钠干燥, 减压蒸去溶剂, 粗产品柱层析分离 $\left(V_{\text {乙配乙酶 }}: V_{\text {石洫酸 }}=2: 1\right)$ 得到相应的目标产物.

$3 \beta$ - 羟基-7-甲氧肜醚鹅去氧胆酸甲酯 (11): 以 $\mathrm{NH}_{2} \mathrm{OCH}_{3} \cdot \mathrm{HCl}$ 作为含氮试剂, 得到白色固体产物, 产
率 82\%. m.p. 83 85 ${ }^{\circ} \mathrm{C} ;{ }^{1} \mathrm{H}$ NMR $\left(\mathrm{CDCl}_{3}, 300 \mathrm{MHz}\right) \delta$ : $0.61\left(\mathrm{~s}, 3 \mathrm{H}, 18-\mathrm{CH}_{3}\right), 0.88\left(\mathrm{~d}, J=6.3 \mathrm{~Hz}, 3 \mathrm{H}, 21-\mathrm{CH}_{3}\right)$, $1.00\left(\mathrm{~s}, 3 \mathrm{H}, 19-\mathrm{CH}_{3}\right), 2.91(\mathrm{dd}, J=12.6,1.5 \mathrm{~Hz}, 1 \mathrm{H}$, C6-H), 3.53 (dddd, $J=15.6,10.8,6.0,4.8 \mathrm{~Hz}, 1 \mathrm{H}, \mathrm{C} 3-\alpha \mathrm{H}$ ), $3.61\left(\mathrm{~s}, 3 \mathrm{H}, \mathrm{COOCH}_{3}\right), 3.72\left(\mathrm{~s}, 3 \mathrm{H}, \mathrm{NOCH}_{3}\right) ;{ }^{13} \mathrm{C} \mathrm{NMR}$ $\left(\mathrm{CDCl}_{3}, 75 \mathrm{MHz}\right) \delta: 174.7$ (24-C), 159.6 (7-C), $70.8(3-\mathrm{C})$, $60.9\left(\mathrm{NOCH}_{3}\right), 54.8(17-\mathrm{C}), 51.5\left(\mathrm{OCH}_{3}\right), 49.4(14-\mathrm{C})$, 44.5 (13-C), 42.9 (9-C), 42.7 (8-C), 42.2 (10-C), 39.1 (12-C), 36.6 (4-C), 35.3 (5-C), 35.1 (20-C), 34.5 (1-C), 30.9 (22-C), 30.0 (23-C), 28.2 (2-C), 28.1 (16-C), 25.2 (6-C), 23.2 (15-C), 21.0 (21-C), 18.4 (19-C), 12.0 (18-C); IR (KBr) v: 3382, 2933, 2864, 1736, 1629, 1446, 1376, $1258,1155,1057 \mathrm{~cm}^{-1}$; HREIMS calcd for $\mathrm{C}_{26} \mathrm{H}_{43} \mathrm{NNaO}_{4}$ $[\mathrm{M}+\mathrm{Na}]^{+}$456.3090, found 456.3077 .

$3 \beta$ - 羟基-7-芐氧肜醚鹅去氧胆酸甲酯 (12)：以 $\mathrm{NH}_{2} \mathrm{OCH}_{2} \mathrm{C}_{6} \mathrm{H}_{5} \bullet \mathrm{HCl}$ 作为含氮试剂, 得到白色固体产物, 产率 $82 \%$. m.p. $83 \sim 85{ }^{\circ} \mathrm{C} ;{ }^{1} \mathrm{H}$ NMR $\left(\mathrm{CDCl}_{3}, 300 \mathrm{MHz}\right)$ $\delta$ : $0.65\left(\mathrm{~s}, 3 \mathrm{H}, 18-\mathrm{CH}_{3}\right), 0.93\left(\mathrm{~d}, J=6.3 \mathrm{~Hz}, 3 \mathrm{H}, 21-\mathrm{CH}_{3}\right)$, 1.03 (s, $\left.3 \mathrm{H}, 19-\mathrm{CH}_{3}\right), 3.05$ (dd, $J=12.6,1.8 \mathrm{~Hz}, 1 \mathrm{H}, \mathrm{C} 6-\mathrm{H}$ ), 3.54 (dddd, $J=15.3,10.5,6.0,4.5 \mathrm{~Hz}, 1 \mathrm{H}, \mathrm{C} 3-\alpha \mathrm{H}$ ), 3.66 (s, $\left.3 \mathrm{H}, \mathrm{COOCH}_{3}\right), 5.03\left(\mathrm{~d}, J=3.9 \mathrm{~Hz}, 2 \mathrm{H}, \mathrm{OCH}_{2} \mathrm{Ph}\right)$, $7.34 \sim 7.24$ (m, 5H, Ph-H); ${ }^{13} \mathrm{C}$ NMR $\left(\mathrm{CDCl}_{3}, 75 \mathrm{MHz}\right) \delta$ : $174.8 \quad$ (24-C), $160.2 \quad$ (7-C), $138.8 \quad$ (1'-Ph-C), 128.2 (2',3',5',6'-Ph-C), 127.4 (4'-C), 75.2 (Ph-C-O), 70.8 (3-C), 54.8 (17-C), $51.5\left(\mathrm{OCH}_{3}\right), 49.5$ (14-C), 44.7 (13-C), 43.1 (9-C), 42.8 (8-C), 42.3 (10-C), 39.2 (12-C), 36.8 (4-C), 35.4 (5-C), 35.2 (20-C), 34.5 (1-C), 31.0 (22-C), 30.9 (23-C), 30.1 (2-C), 28.5 (16-C), 28.2 (6-C), 25.2 (15-C), 23.2 (11-C), 21.1 (21-C), 18.4 (19-C), 12.0 (18-C); IR (KBr) $v$ : 3534, 2945, 2859, 1723, 1654, 1425, 1368, 1217, 1156, $1045 \mathrm{~cm}^{-1}$; ESI-MS m/z: $510.3(\mathrm{M}+\mathrm{Na})^{+}$. HREIMS calcd for $\mathrm{C}_{32} \mathrm{H}_{47} \mathrm{NNaO}_{4}[\mathrm{M}+\mathrm{Na}]^{+} 532.3403$, found 532.3403 .

$3 \beta$-差基-7-缩氨硫脲基我去氧胆酸甲酯(13)：以氨 基硫脲作为含氮试剂, 得到浅黄色固体产物 13, 产率 $76 \%$. m.p. $145 \sim 147{ }^{\circ} \mathrm{C} ;{ }^{1} \mathrm{H}$ NMR (DMSO, $300 \mathrm{MHz}$ ) $\delta$ : 0.63 (s, 3H, 18- $\left.\mathrm{CH}_{3}\right), 0.89$ (d, J=5.4 Hz, 3H, 21- $\mathrm{CH}_{3}$ ), 1.03 (s, 3H, 19- $\mathrm{CH}_{3}$ ), 2.88 (d, $\left.J=12.9 \mathrm{~Hz}, 1 \mathrm{H}, \mathrm{C} 6-\mathrm{H}\right), 3.58$ (s, 3H, $\left.\mathrm{OCH}_{3}\right), 4.54$ (br s, $\left.1 \mathrm{H}, \mathrm{C} 3-\alpha \mathrm{H}\right), 7.26\left(\mathrm{~s}, 1 \mathrm{H}, \mathrm{NH}_{2}\right.$ ), 8.05 (s, $1 \mathrm{H}, \mathrm{NH}_{2}$ ) 10.06 (s, $\left.1 \mathrm{H}, \mathrm{NH}\right) ;{ }^{13} \mathrm{C}$ NMR (DMSO, $75 \mathrm{MHz}) \delta$ : $179.1(\mathrm{C}=\mathrm{S}), 174.2$ (24-C), 157.4 (7-C), 69.5 (3-C), 54.6 (17-C), $51.7\left(\mathrm{OCH}_{3}\right), 49.1$ (14-C), 45.4 (9-C), 44.0 (13-C), 43.5 (8-C), 42.8 (5-C), 39.0 (10-C), 36.7 (12-C), 35.5 (4-C), 35.0 (20-C), 34.5 (1-C), 31.0 (22-C), 30.8 (23-C), 30.7 (2-C), 30.5 (6-C), 28.3 (16-C), 25.5 
(15-C), 23.5 (11-C), 21.3 (21-C), 18.8 (19-C), 12.4 (18-C); IR (KBr) v: 3525, 3423, 3252, 3203, 3137, 2945, 2859, 1711, 1585, 1503, 1454, 1376, 1307, 1258, 1082, 1012 $\mathrm{cm}^{-1}$; ESI-MS $\mathrm{m} / z$ : $478.3(\mathrm{M}+1)^{+}$; HREIMS calcd for $\mathrm{C}_{26} \mathrm{H}_{44} \mathrm{~N}_{3} \mathrm{O}_{3} \mathrm{~S}[\mathrm{M}+\mathrm{H}]^{+}$478.3103, found 478.3123.

$3 \beta$-差基-7-(4'-甲基氨基硫腙基)鹅去氧胆酸甲酯 (14): 以 $\mathrm{NH}_{2} \mathrm{NHCSNHCH}_{3}$ 作为含氮试剂, 得到浅黄色 固体产物, 产率 $73 \%$. m.p. $145 \sim 147{ }^{\circ} \mathrm{C} ;{ }^{1} \mathrm{H}$ NMR $\left(\mathrm{CDCl}_{3}, 300 \mathrm{MHz}\right) \delta: 0.66$ (s, 3H, 18- $\left.\mathrm{CH}_{3}\right), 0.92$ (d, $J=6.0$ $\left.\mathrm{Hz}, 3 \mathrm{H}, 21-\mathrm{CH}_{3}\right), 1.07$ (s, $\left.3 \mathrm{H}, 19-\mathrm{CH}_{3}\right), 3.20$ (d, J=4.8 Hz, $\left.3 \mathrm{H}, \mathrm{NCH}_{3}\right), 3.66 \sim 3.56(\mathrm{~m}, 1 \mathrm{H}, \mathrm{C} 3-\alpha \mathrm{H}), 3.66(\mathrm{~s}, 3 \mathrm{H}$, $\left.\mathrm{OCH}_{3}\right), 7.37$ (q, $\left.J=4.8 \mathrm{~Hz}, 1 \mathrm{H}, \mathrm{CS}-\mathrm{NH}-\mathrm{CH}_{3}\right), 8.81(\mathrm{~s}, 1 \mathrm{H}$, $\mathrm{N}-\mathrm{NH}-\mathrm{CS}) ;{ }^{13} \mathrm{C} \mathrm{NMR}\left(\mathrm{CDCl}_{3}, 75 \mathrm{MHz}\right) \delta: 178.9(\mathrm{C}=\mathrm{S})$, 174.7 (24-C), 156.1 (7-C), 70.4 (3-C), 54.7 (17-C), 51.5 (14-C), $49.3\left(\mathrm{OCH}_{3}\right), 45.3$ (9-C), 44.1(13-C), $43.6(8-\mathrm{C})$, 42.8 (5-C), 38.8 (10-C), 36.5 (12-C), 35.6 (4-C), 35.1 (20-C), 34.2 (1-C), 31.2 (N-C), 30.9 (22-C), 30.8(23-C), 30.4 (2-C), 29.8 (6-C), 28.2 (16-C), 25.5 (15-C), 23.2 (11-C), 21.2 (21-C), 18.4 (19-C), 12.1 (18-C); IR (KBr) v: 3374, 2941, 1868, 1736, 1634, 1564, 1503, 1442, 1376, 1307, 1241, 1172, 1061, 1017, 914, 804, 730, 600, 563 $\mathrm{cm}^{-1}$; ESI-MS $m / z$ : $514.3(\mathrm{M}+23)^{+}$; HREIMS calcd for $\mathrm{C}_{27} \mathrm{H}_{45} \mathrm{~N}_{3} \mathrm{NaOS}[\mathrm{M}+\mathrm{Na}]^{+} 514.3079$, found 514.3080.

$3 \beta$ - 差基-7-(4'-苯基氨基硫腙基)我去氧胆酸甲酯 (15): 以 $\mathrm{NH}_{2} \mathrm{NHCSNHC}_{6} \mathrm{H}_{5}$ 作为含氮试剂, 得到浅黄色 固体产物, 产率 $65 \%$. m.p. $145 \sim 147{ }^{\circ} \mathrm{C} ;{ }^{1} \mathrm{H}$ NMR $\left(\mathrm{CDCl}_{3}, 300 \mathrm{MHz}\right) \delta: 0.66\left(\mathrm{~s}, 3 \mathrm{H}, 18-\mathrm{CH}_{3}\right), 0.92(\mathrm{~d}, J=6.0$ $\left.\mathrm{Hz}, 3 \mathrm{H}, 21-\mathrm{CH}_{3}\right), 1.04$ (s, 3H, 19- $\left.\mathrm{CH}_{3}\right), 3.65 \sim 3.55(\mathrm{~m}, 1 \mathrm{H}$, $\mathrm{C} 3-\alpha \mathrm{H}), 3.63$ (s, 3H, $\left.\mathrm{OCH}_{3}\right), 7.15(\mathrm{t}, J=7.2 \mathrm{~Hz}, 1 \mathrm{H}$, 4'-Ph-H), 7.33 (t, $J=7.5 \mathrm{~Hz}, 2 \mathrm{H}, 3$ '-Ph-H, 5'-Ph-H), 7.60 (d, $\left.J=7.8 \mathrm{~Hz}, 2 \mathrm{H}, 2^{\prime}-\mathrm{Ph}-\mathrm{H}, 6^{\prime}-\mathrm{Ph}-\mathrm{H}\right), 9.17$ (s, 1H, NNHCS), 9.34 (s, 1H, CS-NH-Ph); ${ }^{13} \mathrm{C} \mathrm{NMR}\left(\mathrm{CDCl}_{3}, 75 \mathrm{MHz}\right)$ $\delta: \quad 175.8 \quad(\mathrm{C}=\mathrm{S}), 174.7 \quad$ (24-C), $157.0 \quad$ (7-C), 138.1 (1'-Ph-C), 128.7 (3'-Ph-C, 5'-Ph-C), 125.5 (4'-Ph-C), 123.3 (2'-Ph-C, 6'-Ph-C), 70.4 (3-C), 54.9 (17-C), 51.5 (14-C), $49.5\left(\mathrm{OCH}_{3}\right), 45.4$ (9-C), 44.2 (13-C), 43.5 (8-C), 42.9 (5-C), 38.9 (10-C), 36.4 (12-C), 35.5 (4-C), 35.3 (20-C 15-C), 34.3 (1-C), 31.1 (22-C), 31.0 (23-C), 30.8 (2-C), 29.8 (6-C), 28.2 (16-C), 25.8 (15-C), 23.2 (11-C), 21.2 (21-C), 18.4 (19-C), 12.2 (18-C); IR (KBr) v: 3293, 2941, 2872, 1732, 1593, 1540, 1442, 1298, 1176, 1102, 996, 747, $690,600 \mathrm{~cm}^{-1}$; HREIMS calcd for $\mathrm{C}_{32} \mathrm{H}_{47}-\mathrm{N}_{3} \mathrm{NaO}_{3} \mathrm{~S}[\mathrm{M}+$ $\mathrm{Na}]^{+} 576.3236$, found 576.3220 .

$3 \beta$-差基-7-[4'-(2"-甲基)苯基]氨基硫腙基鹅去氧胆 酸甲酯(16): 以 $\mathrm{NH}_{2} \mathrm{NHCSNHC}_{6} \mathrm{H}_{4} \mathrm{CH}_{3}$ 作为含氮试剂,
得到浅黄色固体产物, 产率 $65 \%$. m.p. $145 \sim 147{ }^{\circ} \mathrm{C} ;{ }^{1} \mathrm{H}$ $\mathrm{NMR}\left(\mathrm{CDCl}_{3}, 300 \mathrm{MHz}\right) \delta: 0.69\left(\mathrm{~s}, 3 \mathrm{H}, 18-\mathrm{CH}_{3}\right), 0.94(\mathrm{~d}$, $\left.J=6.0 \mathrm{~Hz}, 3 \mathrm{H}, 21-\mathrm{CH}_{3}\right), 1.11$ (s, 3H, 19- $\left.\mathrm{CH}_{3}\right), 2.32$ (s, 3H, Ph- $\left.\mathrm{CH}_{3}\right), 2.62(\mathrm{~d}, J=12.9 \mathrm{~Hz}, 1 \mathrm{H}, \mathrm{C} 6-\mathrm{H}), 3.68-3.58$ (m, $1 \mathrm{H}, \mathrm{C} 3-\alpha \mathrm{H}), 3.66\left(\mathrm{~s}, 3 \mathrm{H}, \mathrm{OCH}_{3}\right), 7.28 \sim 7.15(\mathrm{~m}, 3 \mathrm{H}$, 4',5',6'-Ph-H), 7.91 (d, J=7.8 Hz, 1H, 3'-Ph-H), 9.07 (s, 1H, N-NH-CS), 9.13 (s, 1H, CS-NH-Ph); ${ }^{13} \mathrm{C}$ NMR $\left(\mathrm{CDCl}_{3}, 75 \mathrm{MHz}\right) \delta: 176.8(\mathrm{C}=\mathrm{S}), 174.7$ (24-C), 156.9 (7-C), 136.6 (1'-Ph-C), 132.4 (3'-Ph-C), 130.5 (5'-Ph-C), 126.5 (2'-Ph-C), 126.4 (4'-Ph-C), 126.2 (6'-Ph-C), 70.5 (3-C), 54.8 (17-C), 51.5 (14-C), $49.3\left(\mathrm{OCH}_{3}\right), 45.5$ (9-C), 44.3 (13-C), 43.6 (8-C), 42.8 (5-C), 38.8 (10-C), 36.6 (12-C), 35.6 (4-C), 35.2 (20-C), 34.2 (1-C), 31.0 (22-C), 30.9 (23-C), 30.8 (2-C), 29.8 (6-C), 28.1 (16-C), 25.6 (15-C), 23.2 (11-C), 21.2 (21-C), 18.4 (19-C), 17.9 $\left(\mathrm{PhCH}_{3}\right), 12.2$ (18-C); IR (KBr) v: 3387, 3313, 2933, 2868, $1732,1642,1585,1527,1486,1450,1380,1364,1298$, 1298, 1268, 1204, 1168, 1106, 1066, $1012 \mathrm{~cm}^{-1}$; HREIMS calcd for $\mathrm{C}_{33} \mathrm{H}_{49} \mathrm{~N}_{3} \mathrm{NaO}_{3} \mathrm{~S}[\mathrm{M}+\mathrm{Na}]^{+}$590.3392, found 590.3396 .

\section{2 体外抗肿瘤活性研究}

使用顺铂 (Cisplatin) 作为阳性对照, 采用 MTT (methyl thiazolyl tetrazolium)法测试所合成的目标化合 物对人胃癌细胞(SGC-7901)、人肝癌细胞(Bel-7404)和 人体前列腺癌细胞株(PC-3) 的体外生长增殖抑制活 性 ${ }^{[19]}$. 所有细胞分别采用 RPMI-1640 培养液(加入 $10 \%$ 牛血清和 $0.1 \mathrm{~g} / \mathrm{L}$ 青霰素 $\mathrm{G}+0.1 \mathrm{~g} / \mathrm{L}$ 硫酸链霉素)在 $37{ }^{\circ} \mathrm{C}$ 于 $5 \% \mathrm{CO}_{2}$ 的潮湿气氛中培养.

实验步骤如下: 首先将有机化合物溶解在 DMSO 中, 配制成 $10 \mathrm{mg} / \mathrm{mL}$ 的 DMSO 溶液保存在冰箱; 将对 数生长期的肿瘤细胞分别以约 $(3 \sim 4) \times 10^{4}$ 个 $/ \mathrm{mL}$ 的密 度接种于 96 孔板中, 每孔接种 $200 \mu \mathrm{L}$, 置于 $\mathrm{CO}_{2}$ 培养 箱中培养 $24 \mathrm{~h}$; 按预设的浓度梯度(最高浓度设为 $80 \mu \mathrm{g} /$ $\mathrm{mL}$ )加入待测样品, 每一浓度梯度设 3 个平行孔, 同时 分别采用顺铂作为阳性对照和等量的 DMSO 作为空白 对照; 在二氧化碳培养箱中于 $37{ }^{\circ} \mathrm{C}$ 培养 $72 \mathrm{~h}$ 后, 每孔 加入 $20 \mu \mathrm{L}$ 的 MTT $(5 \mathrm{mg} / \mathrm{mL})$, 然后在二氧化碳培养箱 中继续温育 $4 \mathrm{~h}$; 抽取上清液, 然后加入 $200 \mu \mathrm{L}$ 的 DMSO, 在振动器上震荡 $10 \mathrm{~min}$ 溶解沉淀, 随后用酶标 仪在 $490 \mathrm{~nm}$ 波长测定 $\mathrm{OD}$ 值. 通过下式求出样品一定浓 度下样品对细胞的抑制率:

抑制率 $(\%)=[($ 对照 $\mathrm{OD}$ 一空白 OD $)-($ 给药 $\mathrm{OD}$ 一空

白 OD) $] /($ 对照 OD一空白 OD) $\times 100 \%$

然后以抑制率对药物浓度作图, 求出每个样品的 $\mathrm{IC}_{50}$ 值. 如果化合物在最高浓度没有抑制作用，一般测定一 
次, 其它的每个样品平行测定三次, 计算平均值, 偏差 大的需要进一步测定.

\section{辅助材料(Supporting Information) 化合物的 ${ }^{1} \mathrm{H}$ NMR} 和 ${ }^{13} \mathrm{C}$ NMR 谱图. 这些材料可以免费从本刊网站 (http://sioc-journal.cn/)上下载.

\section{References}

[1] Richard, J. P.; Olga, K. W. Evidence-Based Completmentary Altern. Med. 2005, 2(1), 49.

[2] Dimitrios, T. P. T.; George, D. G.; Catherine, K.; Athanasios, P.; Panayiotis, K.; Charalambos, C. Breast Cancer Res. Treat. 2006, 97, 17.

[3] Dimitrios, T. P. T. Cancer Lett. 2006, 243, 202.

[4] Cui, J.-G.; Liu, L.; Gan, C.-F.; Xiao, Q.; Huang, Y.-M. Prog. Chem. 2014, 26, 320 (in Chinese). (崔建国, 刘亮, 甘春芳, 肖琦, 化学进展, 2014, 26, 320.)

[5] Huang, Y.-M.; Cui, J.-G.; Gan, C.-F.; Yao, Q.-C.; Jia, L.-Y. Prog. Chem. 2012, 24, 61 (in Chinese).

(黄燕敏, 崔建国, 甘春芳, 姚秋翠, 贾琳怡, 化学进展, 2012, 24, 61.)

[6] Chen, S.-J.; Cui, J.-G.; Li, Y.; Fan, L.-H. Chin. J. Org. Chem. 2011, 31,187 (in Chinese).

(陈思静、崔建国、李芗、范良华, 有机化学, 2011, 31, 187.)
[7] Cui, J. G.; Fan, L.; Huang, L. L.; Liu, H. L.; Zhou, A. M. Steroids 2009, 74, 62 .

[8] Cui, J. G.; Fan, L.; Huang, Y. M.; Xin, Y.; Zhou, A. M. Steroids 2009, 74, 989.

[9] Huang, Y. M.; Cui, J. G.; Chen, S. J.; Gan, C. F.; Zhou, A. M. Steroids 2011, 76, 1346.

[10] Huang, Y. M.; Cui, J. G.; Chen, S. J.; Gan, C. F.; Yao, Q. C.; Lin, Q.-F. Bioorg. Med. Chem. Lett. 2013, 23, 2265.

[11] Huang, Y. M.; Cui, J. G.; Chen, S. J.; Lin, Q. F.; Song, H. C.; Gan, C. F.; Su, B.; Zhou, A. M. Mar. Drugs 2014, 12, 1715.

[12] Gan, C. F.; Cui, J. G.; Su, S. Y.; Lin, Q. F.; Jia, L. Y.; Fan, L. H.; Huang, Y. M. Steroids 2014, 87, 99.

[13] Im, E. O.; Choi, Y. H.; Paik, K. J.; Suh, H.; Jin, Y.; Yoo, Y. H.; Kim, N. D. Cancer Lett. 2001, 163, 83.

[14] Im, E. O.; Choi, S. H.; Suh, H.; Choi, Y. H.; Yoo, Y. H.; Kim, N. D. Cancer Lett. 2005, 229, 49.

[15] Sharma, R.; Majer, F.; Peta, V. K.; Wang, J.; Keaveney, R.; Kelleher, D.; Long, A.; Gilmer, J. F. Bioorg. Med. Chem. 2010, 18, 6886.

[16] Becker, S.; Reinehr, R.; Graf, D.; Dahl, S.; Häussinger, D. Cell Physiol. Biochem. 2007, 19, 89.

[17] Qin, C. Y.; Liu, H. Chin. J. Digestion 2007, 27, 124 (in Chinese). (秦成勇, 刘慧, 中华消化杂志, 2007, 27, 124.)

[18] Huang, Y. M.; Yao, Q. C.; Cui, J. G.; Gan, C. F.; Huang, Q. Y.; Su, B.; Zhou, A. M. Chem. Res. Chin. Univ. 2014, 30, 605.

[19] Cui, J. G.; Liu, L.; Zhao, D. D.; Gan, C. F.; Huang, X.; Xiao, Q.; Qi, B. B.; Yang, L.; Huang, Y. M. Steroids 2015, 95, 32. 